\title{
The reasons for the deterioration of chicken eggshell quality at high temperatures: a review
}

\author{
Alexey Kavtarashvili1 ${ }^{1,}$, and Viktor Buyarov ${ }^{2}$ \\ ${ }^{1}$ Laboratory of the Technology of Egg Production, Federal Scientific Center "All-Russian Research and Technological Institute of \\ Poultry" of Russian Academy of Sciences, Sergiev Posad, Russia \\ ${ }^{2}$ Department of Small Animal Science and Farm Animal Breeding, Orel State Agrarian University named after N.V. Parakhin, Orel, \\ Russia
}

\begin{abstract}
In hot-climate regions high ambient temperature is one of the main problems of poultry farming. It is a reason for large financial losses caused by a significant decrease in the livability and productivity of poultry and the quality of products. Poor shell quality results in increased egg breakage and cracking. Such eggs lose the abilities for long-term storage or incubation and their market price is become significantly (1.5-3-fold) reduced. In the review presented the biological role of the eggshell, certain aspects of its formation, and the main reasons for the deterioration of eggshell quality in high ambient temperatures are discussed. It was shown that the eggshell quality depends on the genotype, age, feeding, health status, management conditions, etc. High ambient temperatures (above $32-35{ }^{\circ} \mathrm{C}$ ) disrupt the process of eggshell formation and leads to a significant decrease in its weight, thickness, and strength. The negative impact of high ambient temperature on eggshell quality is associated with a complex set of problems, including low feed intake by hens, acid-base and mineral imbalances, physiological disorders in the endocrine system and other organs and mechanisms involved in the process of eggshell formation. The understanding of these reasons gives an opportunity for the development and implementation of targeted interventions and enables the minimization of negative impact of heat stress on eggshell quality and the efficiency of the commercial egg production.
\end{abstract}

\section{Introduction}

High ambient temperature is one of the main environmental problems of poultry farming in regions with hot climates. It annually leads to large financial losses, mainly caused by a significant decrease in the livability and productivity of poultry, the quality of products [1-6]. The degree of negative impact depends on the strength and duration of exposure to high temperatures, the age of the hens, the type and level of their productivity, veterinary well-being, the quality of feeding, a complex of technological and genetic factors, etc. $[2,7]$.

The shell is the main protective coating of an egg, the main functions of which being mineral nutrition and gas exchange in the embryo, resistance to mechanical and microbial impacts on the egg to preserve its integrity [8, 9]. Poor eggshell quality results in increased egg breakage and cracking, which causes significant economic damage to farms. Eggs with damaged shells lose their abilities for long-term storage or incubation, and their market price is significantly (1.5-3-fold) reduced [10].

The main indicator of the eggshell quality is its strength, which depends on the weight, thickness, chemical composition, and uniformity of distribution of the structural material $[11,12]$.
This work aims to summarize and analyze the currently available scientific knowledge on the reasons for the deterioration of chicken eggshell quality under high-temperature conditions, which could form a conceptual basis for our understanding of the mechanisms associated with this phenomenon.

Some aspects of eggshell formation. The eggshell formation is a complex process and depends on hen genotype, age, feeding, health status, management, etc. $[10,13]$. High eggshell quality can be achieved only under optimal management conditions, the presence and harmonious interaction of all factors influencing this process [14].

The ability of chickens to form good quality shells largely depends on the presence of calcium in the diet and the bone tissue pool [15]. Calcium is the most important feed factor affecting shell quality. The significant need for calcium is explained by the fact that eggshells contain up to $95-96 \%$ of calcium carbonate, the rest is the organic matrix (2-3.5\%), magnesium, phosphorus, and some micronutrients [16, 17]. One eggshell contains about 2.2-3 g of pure calcium [18].

Under optimal conditions of feeding and management of highly productive laying hens three sources of ionic calcium are involved in shell calcification: diet, temporary skeletal pool (medullary

\footnotetext{
* Corresponding author: alexk@,vnitip.ru
} 
tissue), and true skeleton. Normally for the synthesis of an eggshell the share of dietary calcium is about $68 \%$, the share of medullary tissue is $29 \%$, and diffuse calcium extracted from the surface of the bones accounts for about $3 \%[19,20]$.

The dietary calcium is used for the shell formation according to the simple physical laws associated with the permeability of the intestinal walls. The deposited calcium is mobilizing via the interaction of hormones with the liver (vitellogenin) and medullary structures in the bones (calcium). The formation of carbonic acid ions responds to the presence of the carbonic anhydrase enzyme in poultry. The synthesis and metabolic activity of this enzyme is controlled by estrogens and progesterone $[21,22]$. It is assumed that estrogen affects the transport of $\mathrm{Ca}^{2+}$ in the duodenum by increasing the regulation of calcium channels [23], but also by stimulating the conversion of vitamin $\mathrm{D}_{3}$ into its biologically active form calcitriol [24].

Under optimal conditions of management and nutrition during the shell formation the blood flow in the shell gland (uterus) of the oviduct increases 4-5-fold [25]. Calcium absorption occurs mainly in the upper part of the small intestine (in the duodenum), in two ways as a result of active transfer of calcium through the intestinal wall and with the help of a specific calciumbinding protein. Both processes are activated by vitamin $\mathrm{D}_{3}[21,22]$.

In the stomach, under the influence of gastric juice (hydrochloric acid), most of the dietary calcium is converted into calcium chloride $\left(\mathrm{CaCl}_{2}\right)$, which almost immediately dissociates into ions $\left(\mathrm{Ca}^{2+}\right)$. Entering the small intestine, calcium ions react with specific calciumbinding proteins, in particular with calbindin-D28k. The main role of calbindin-D28k is the transfer of ionized calcium from the intestine to the shell gland of the oviduct [26-28]. At a "thermoneutral" temperature (20$26{ }^{\circ} \mathrm{C}$ ), the degree of expression of calbindin-D28k in the intestinal segments of laying hens has the following sequence: duodenum $>$ jejunum $>$ ileum $>$ cecum $>$ large intestine [28, 29].

The concentration of calbindin-D28k in the intestinal tissues and the oviductal gland and the $\mathrm{Ca}^{2+}$ transport are closely correlated [27-30]. Calbindin is found in the intestine before sexual maturity, and noticeably increases by the onset of lay [31]. In the shell gland of the oviduct calbindin appears during the formation of the shell of the first egg and disappears within 3 days after the cease of lay $[30,31]$. Its concentration is proportional to the rate of $\mathrm{Ca}^{2+}$ deposition in the eggshell $[30,32]$. In addition to the proposed role of calbindin in $\mathrm{Ca}^{2+}$ transport it can also be involved in the protection of cells from high $\mathrm{Ca}^{2+}$ concentrations or from cell degradation by apoptosis, and also act as a buffer [33].

Impact of heat stress on the eggshell quality. High ambient temperature or so-called heat stress (above 32$35^{\circ} \mathrm{C}$ ) disrupts the formation of eggshell and leads to a significant decreases in the absolute and relative weight [28], thickness, and strength of the eggshell [34]. The shell quality deteriorates due to the violation of the microstructure of both its organic and mineral parts [35].
Under heat stress peripheral vessels reflexively expand. The blood flow to the skin and other external integuments increases with a simultaneous decrease in blood supply to internal organs, including intestine, ovary, and oviduct, which is a compensatory physiological response that helps the body of a hen to cope with the excessive external heat load [36].

In addition, to restore the heat balance with the environment the bird spreads its wings, reduces activity, while its respiration depth decreases approximately 5-6fold, while the respiration rate increases $[2,37]$.

Frequent breathing helps the bird to reduce body temperature by evaporative cooling, but at the same time it increases the excretion of carbon dioxide $\left(\mathrm{CO}_{2}\right)$, which is necessary for the formation of calcium carbonate, which is a component of the eggshell [38]. As a result, blood $\mathrm{pH}$ increases, and the partial pressure of carbon dioxide in arterial blood $\left(\mathrm{pCO}_{2}\right)$ decreases, which in turn causes a disturbance in the circulatory acid-base balance with its shift to the alkaline side, namely, respiratory alkalosis [39]. Respiratory alkalosis at high ambient temperatures is characterized by low blood concentrations of calcium, sodium bicarbonate $\left(\mathrm{NaHCO}_{3}\right)$, carbonic acid $\left(\mathrm{H}_{2} \mathrm{CO}_{3}\right)$, and bicarbonate ions $\left(\mathrm{HCO}_{3}^{-}\right)[40,41]$.

A change in the ratio of electrolytes and blood gases has a negative impact on the formation of a high-quality eggshell $[6,42]$. The process is further aggravated by the fact that heat stress suppresses the activity of the thyroid gland, which prevents the formation of the active form of vitamin $\mathrm{D}_{3}$ in the kidneys $[35,43]$.

The formation of poor quality shells as a result of low level of $\mathrm{Ca}$ in plasma at high ambient temperatures can be associated with a decrease in blood flow to the egg-forming organs in hens under thermal stress [44]. Obviously, insufficient blood flow will reduce the supply of calcium, oxygen and other nutrients to the egg production organs, which are necessary for the optimal physiological functioning of these extremely important organs for the formation of a high-quality shell, resulting in negative consequences.

It is believed that any decrease in shell thickness that occurs with an increase in respiration rate is almost certainly associated with a decrease in the ability of blood to carry $\mathrm{Ca}$ as a result of alkalosis [45].

High temperatures also disrupt the mineral balance of birds, and its degree depends on the type of mineral and the severity of heat stress. It was found that heat stress significantly increases the excretion of certain minerals (phosphorus, potassium, sulfur, copper, zinc, molybdenum and magnesium) [46], $\mathrm{Na}^{+}$and $\mathrm{K}^{+}$, which (along with $\mathrm{Cl}^{-}$) play an important role in homeostasis of acid-alkaline balance of hens and regulation of osmotic pressure [47]. Other authors have also shown a decrease in plasma electrolytes with an increase in ambient temperature [48]. It can be assumed that the reason for the increased excretion of electrolytes is a significant increase (3-5-fold) in water consumption during heat stress.

Some mechanisms that can explain the deterioration of eggshell quality in laying hens under heat stress are discussed in literature. One of them is a decrease in the 
activity of the carbonic anhydrase, which catalyzes the formation of bicarbonate ions from carbon dioxide and water, which are converted in the shell gland into eggshell's calcium carbonate [49].

The deterioration of the chicken eggshell quality at high temperatures is partly explained by a decrease in feed intake $[43,50,51]$, and at the same time calcium [52] by $25-30 \%$, as well as by an increase in water consumption and accelerated passage of feed through the gastrointestinal tract [43].

Under the influence of heat stress against the background of a decrease in feed consumption, the weight of the small intestine decreases by $22-23 \%$ and the absorbing surface of the intesstinal villi by $19 \%$ [53, 54]. High temperature leads to imbalance between the production of reactive oxygen species (ROS) and the antioxidant defense system, which results in the damages to the epithelium and to inflammatory reaction of the intestinal mucosa [55]. Other changes which can occur in the gastrointestinal tract include the decreases in the acidity and bactericidal properties of gastric juice and the shift of the balance of beneficial and harmful intestinal microflora towards an increased content of pathogenic microbial species [56, 57].

It should also be noted that under high temperature conditions the localization of the calcium-binding protein calbindin-D28k is significantly reduced in the ileum, cecum, colon, and in the shell gland (uterus) of the oviduct. It is probably partly associated with a decrease in the secretion of estrogens [28], which, as suggested by some authors [58], are involved in the induction of the synthesis of calbindin-D28k.

In addition, low calcium intake during heat stress causes bone resorption and hyperphosphatemia. An increase in the content of phosphorus in the blood suppresses the formation of calcium carbonate $\left(\mathrm{CaCO}_{3}\right)$ in the shell gland of the chicken oviduct due to the outflow of blood to the skin to cool the body, thereby reducing blood flow to the uterus and its "calcium nutrition"; as a result, the eggshell quality deteriorates $[35,50]$. Given that most of the calcium for the formation of eggshells comes from the diet, it can be concluded that any factor (for example, high ambient temperature) that causes a decrease in feed intake will simultaneously lead to a decrease in the level of calcium intake, its mobilization and availability, and hence directly contribute to a decrease in eggshell quality.

\section{Conclusion}

Analysis of numerous available studies shows that the negative impact of high ambient temperature on the eggshell quality is associated with a complex set of problems. These problems include low feed intake, acidbase and mineral imbalances in the body, physiological disorders in the functioning of the endocrine system and other organs and mechanisms involved in the eggshell formation process. The understanding of these reasons gives an opportunity for the development and implementation of targeted interventions. This will enable to minimize the negative impact of heat stress on eggshell quality and the efficiency of the commercial egg production.

\section{References}

1. G.D. Vandana, V. Sejian, A.M. Lees, P. Pragna, M.V. Silpa, K.S. Maloney, Heat stress and poultry production: impact and amelioration, International Journal of Biometeorology, 65(2), 163-179 (2021).

2. L.J. Lara, M.R. Rostagno, Impact of heat stress on poultry production, Animals 3(2), 356-369 (2013).

3. Z. Abidin, A. Khatoon, Heat stress in poultry and the beneficial effects of ascorbic acid (vitamin C) supplementation during periods of heat stress, World's Poult. Sci. J., 69, 135-151 (2013).

4. V.I. Fisinin, A. Sh. Kavtarashvili, Heat Stress in Poultry. Report II. Methods and techniques for prevention and mitigation (review), Sel'skokhozyaystvennaya biologiya, 50 (4), 431-443 (2015).

5. A. Nawab, F. Ibtisham, G. Li, B. Kieser, J. Wu, W. Liu, Y. Zhao, Y. Nawab, K. Li, M. Xiao, L. An, Heat stress in poultry production: Mitigation strategies to overcome the future challenges facing the global poultry industry, Journal of Thermal Biology, 78, 131-139 (2018).

6. M.R. Farag, M. Alagawany, Physiological alterations of poultry to the high environmental temperature, Journal of Thermal Biology, 76, 101-106 (2018).

7. V.I. Fisinin, A. Sh. Kavtarashvili, Heat Stress in Poultry. Report I. Danger, physiological changes in the body, signs and manifestations (review), Sel'skokhozyaystvennaya biologiya, 50(2), 162-171 (2015a).

8. P.P. Tsarenko, Improving the quality of poultry products. Food and hatching eggs, Leningrad, Agropromizdat, 240 (1988).

9. E.V. Osipova, Improvement of methods for assessing the strength of the shell of chicken eggs: thesis for the degree of Cand. of agricultural sciences, St. Petersburg, 117 (2017).

10. M. Ketta, E. Tůmová, Eggshell structure, measurements, and quality-affecting factors in laying hens, Czech J. Anim. Sci., 61(7), 299-309 (2016).

11. A. Kavtarashvili, T. Okolelova, Ways to reduce the breakage and cracking of eggs in industrial poultry farming, Animal feeding and fodder production, 10, 4247 (2007).

12. P.P. Tsarenko, L.T. Vasilieva, E.V. Osipova, Strength is the main quality of the shell, Poultry and poultry products, 5, 51-54 (2012).

13. Sh.A. Imangulov, A. Sh. Kavtarashvili, M.L. Bebin, Improving the Quality of Eggs, Sergiev Posad, 30 (1999).

14. A. Dhawale, Abnormal eggs cause subnormal profits, World Poult., 24(6), 20 (2008). 
15. M. Farmer, SR., D.A. Ronald, M.K. Eckme, Calcium metabolism in broiler breeder hens. 2. The influence of the time of feeding on calcium status of the digestive system and egg shell quality, Poultry Sci., 62(3), 465-461 (1983).

16. Y. Nys, J. Gautron, J.M. Garcia-Ruiz, M.T. Hincke, Avian eggshell mineralization: biochemical and functional characterization of matrix proteins, Comptes Rendus Palevol, 3, 549-562 (2004).

17. Y. Nys, J. Gautron, Structure and formation of the eggshell, In: Huopalahti R., Lopez-Fandino R., Anton M., Schade R. (eds): Bioactive Egg Compounds, Springer-Verlag, Berlin, Heidelberg, 99-104 (2007).

18. J.R. Roberts, Factors affecting eggshell and internal egg quality, In: Proc. 18th Annual ASAIM SE Asian Feed Technology and Nutrition Workshop, Le Meridien Siem Reap, Cambodia, 1-9 (2010).

19. C.C. Whitehead, Nutrition and poultry welfare, World's Poult. Sci. J., 58(3), 349-356 (2002).

20. V.I. Fisinin, I.A. Egorov, T.M. Okolelova, Sh. A. Imangulov, Scientific Foundations of Poultry Feeding, Sergiev Posad, 352 (2009).

21. F. Bronner, Intestinal calcium absorption: mechanisms and applications, Journal Nutrition, 117(8), 1347-1352 (1987).

22. L.I. Podobed, Guide to calcium-phosphorus nutrition of farm animals and poultry: monograph, Odessa: Pechatnyi Dom, 410 (2005).

23. S.J. Van Cromphaut, K. Rummens, I. Stockmans, E. Van Herck. F.A. Dijcks, A.G. Ederveen, P. Carmeliet, J. Verhaeghe, R. Bouillon, G. Carmeliet, Intestinal Calcium Transporter Genes Are Upregulated by Estrogens and the Reproductive Cycle Through Vitamin D Receptor-Independent Mechanisms, Journal of Bone and Mineral Research, 18(10), 1725-1736 (2003).

24. L. Castillo, Y. Tanaka, H.F. DeLuca, M.L. Sunde, The stimulation of 25-hydroxyvitamin D3-1[alpha]hydroxylase by estrogen, Archives of Biochemistry and Biophysics, 179(1), 211-217 (1977).

25. D. Wolfenson, Y.F. Frei, A. Berman, Responses of the reproductive vascular system during the eggformation cycle of unanaesthetised laying hens, British Poult. Sci., 23(5), 425-431 (1982).

26. A. Bar, Differential regulation of calbindin in the calcium-transporting organs of birds with high calcium requirements, Jpn. Poult. Sci.,46(4), 267-285 (2009).

27. A. Bar, Calcium transport in strongly calcifying laying birds: Mechanisms and regulation Comp (Review), Biochem. Physiol. A Mol. Integr. Physiol., 152(4), 447-469 (2009a).

28. T.A. Ebeid,T. Suzuki, T. Sugiyama, High ambient temperature influences eggshell quality and calbindinD28k localization of eggshell gland and all intestinal segments of laying hens, Poultry Sci., 91(9), 2282-2287 (2012).

29. T. Sugiyama, H. Kikuchi, S. Hiyama, K. Nishizawa, S. Kusuhara, Expression and localisation of calbindin
D28k in all intestinal segments of the laying hen, Br. Poult. Sci., 48(2), 233-238 (2007).

30. A. Bar, S. Striem, E. Vax, H. Talpaz, S. Hurwitz, Regulation of calbindin mRNA and calbindin turnover in intestine and shell gland of the chicken, Am. J. Physiol., 262(5), R800-R805 (1992).

31. S. Striem, A. Bar, Modulation of quail intestinal and egg shell gland calbindin (Mr 28,000) gene expression by vitamin D3, 1,25-dihydroxyvitamin D3 and egg laying Mol, Cell. Endocrinol., 75(2), 169-177 (1991).

32. S. Yosefi, R. Braw-Tal, A. Bar, Intestinal and eggshell calbindin and bone ash as influenced by age of the laying hen and molting Comp, Biochem. Physiol. A Mol. Integr. Physiol., 136(3), 673-682 (2003).

33. S. Christakos, F. Barletta, M. Huening, P. Dhawan, Y. Liu, A. Porta, X. Peng, Vitamin D target proteins: Function and regulation, J. Cell. Biochem., 88(2), 238244 (2003).

34. H. Lin, K. Mertens, B. Kemps, T. Govaerts, B. De Ketelaere, J. De Baerdemaeker, E. Decuypere, J. Buyse, New approach of testing the effect of heat stress on eggshell quality: Mechanical and material properties of eggshell and membrane, Br. Poult. Sci. 45(7), 476-482 (2004).

35. A.Sh. Kavtarashvili, T.N. Kolokolnikova, Consequences of Heat Stress in Poultry. Methods of prevention, Proceedings of the International Veterinary Congress "Actual veterinary problems in the poultry industry", Moscow, 129-132 (2013).

36. R.U. Khan, S. Naz, Z. Nikousefat, M. Selvaggi, V. Laudadio, V. Tufarelli, Effect of ascorbic acid in heatstressed poultry, World's Poult. Sci. J., 68(3), 477-489 (2012).

37. A.O. Oguntunji, O.M. Alabi, Influence of high environmental temperature on egg production and shell quality: a review, World's Poult. Sci. J., 66(4), 739-749 (2010).

38. S.P. He , M.A. Arowolo , R.F. Medrano, S. Li , Q.F. Yu , J.Y. Chen, J.H. He, Impact of heat stress and nutritional interventions on poultry production, World's Poult. Sci. J., 74(4), 647-664 (2018).

39. K.P. Mahmoud, M.M. Beck, S.E. Scheideler, M.F. Forman, K.P. Anderson, S.D. Kachman, Acute high environmental temperature and calcium-oestrogen relationship in the hen, Poultry Sci., 75, 1555-1562 (1996).

40. S.A. Borges, A.V. Fischer DA Silva, A. Majorka, D.M. Hooge, K.R. Cummings, Physiological responses of broiler chicken to heat stress and electrolyte balance (sodium plus potassium minus chloride, milliequivalent per kilogram), Poultry Sci., 83(9), 1551-1558 (2004).

41. R.G. Teeter, M.O. Smith, F.N. Owens, C. Arp, S. Sangiah, J.E. Breazile, Chronic heat stress and respiratory alkalosis: occurrence and treatment in broiler chickens, Poultry Sci., 64(6), 1060-1064 (1985).

42. A. Allahverdi, A. Feizi, H.A. Takhtfooladi, H. Nikpiran, Effects of heat stress on acid-alkali imbalance, plasma calcium concentration, egg production and egg 
quality in commercial layer, Global Veterinaria, 10(2), 203-207 (2013).

43. A.Sh. Kavtarashvili, Sh.A. Imangulov, T.M. Okolelova, Possible Solutions to the Problem of Egg Shell Quality in Poultry Farms, Poultry and Poultry Products, 4, 22-25 (2003).

44. I. Rozenboim, E. Tako, O. Gal-Garber, J.A. Proudman, Z. Uni, The effect of heat stress on ovarian function of laying hens, Poultry Sci., 86(8), 1760-1765 (2007).

45. P.F. Suray, T.I. Fotina, Physiological mechanisms of stress development in poultry farming, Livestock today, 6, 54-60 (2013).

46. T. Belay, C.J. Wiernusz, R.G. Teeter, Mineral balance and urinary and fecal mineral excretion profile of broilers housed in thermoneutral and heat-distressed environments, Poultry Sci., 71(6), 1043-1047 (1992).

47. S.A. Borges, A.V. Fischer da Silva, J. Ariki, D.M. Hooge, K.R. Cummings, Dietary electrolyte balance for broiler chickens under moderately high ambient temperatures and relative humidities, Poultry Sci., 82(2), 301-308 (2003).

48. A. Pavlik, M. Lichovnikova, P. Jelinek, Blood plasma mineral profile and qualitative indicators of the eggshell in laying hens in different housing systems, Acta Vet. Brno., 78(3), 419-429 (2009).

49. D. Balnave, I. Yosellewiz, R. Dixon, Physiological changes associated with the production of defective eggshells by hens receiving sodium chloride in the drinking water, British J. of Nutrit., 61(1), 35-53 (1989).

50. H.V.S. Chauhan, S. Roy, Nutritional Diseases. In: Poultry Diseases Diagnosis and Treatment, 3rd Ed. New Age International (P) Ltd., Publisher New Delhi, 172 (2007).

51. O.A. Elijah, A. Adedapo, The effect of climate on poultry productivity in Ilorin, Kwara State, Nigeria, International J. of Poult. Sci., 5(11), 1061-1068 (2006).

52. J.L. Robert, Factors affecting egg internal quality and shell quality, Journal of Applied Sci., 41(3), 161-177 (2004).

53. W.G. Bottie, P.C. Harrison, Celiac cyclic blood flow pattern response to feeding and heat exposure, Poultry Sci., 66(12), 2039-2042 (1987).

54. M.A. Mitchell, A.J. Carlisle, The effects of chronic exposure to elevated environmental temperature on intestinal morphology and nutrient absorption in the domestic fowl (Gallus domesticus), Comp. Biochem. and Physiol. Part A: Physiology, 101(1), 137-142 (1992).

55. G.P. Lambert, C.V. Gisolfi, D.J. Berg, P.L. Moseley, L.W. Oberley, K.C. Kregel, Selected contribution: Hyperthermia-induced intestinal permeability and the role of oxidative and nitrosative stress, J. Appl. Physiol., 92(4), 1750-1761 (2002).

56. T.G. Dinan, J.F. Cryan, Regulation of the stress response by the gut microbiota: Implications for psychoneuroendocrinology, Psychoneuroendocrinology, 37(9), 1369-1378 (2012).
57. M.H. Rostagno, Effects of heat stress on the gut health of poultry, Journal of Animal Science, 98(4), 1-9 (2020).

58. A. Bar, E. Vax, S. Striem, Relationships among age, eggshell thickness and vitamin D metabolism and its expression in the laying hen, Comp. Biochem. Physiol. A Mol. Integr. Physiol., 123(2), 147-154 (1999). 